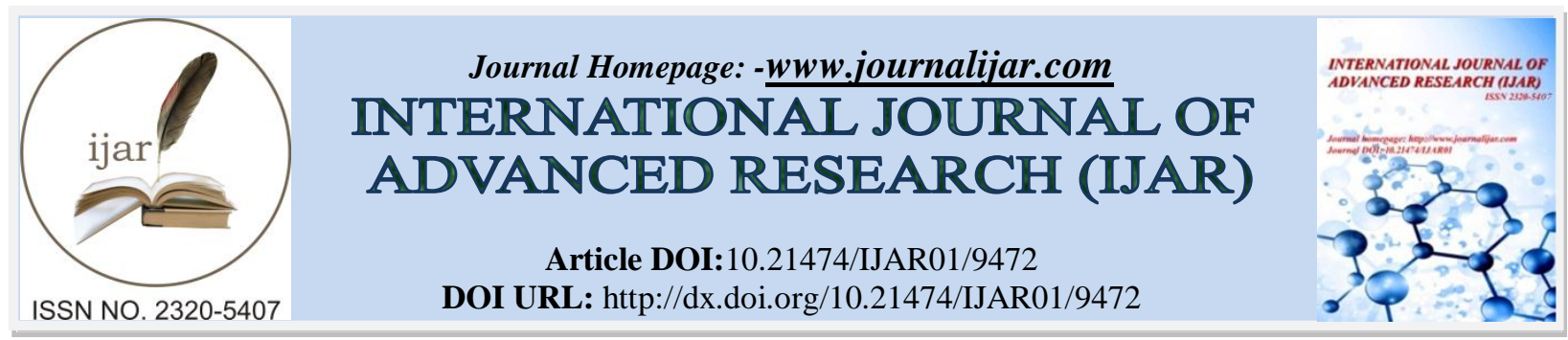

RESEARCH ARTICLE

\title{
MICROVASCULAR COMPLICATIONS OF LEAN TYPE 2 DIABETES MELLITUS WITH SPECIAL REFERENCE TO LIPID PROFILE AND GLYCEMIC STATUS-A HOSPITAL BASED STUDY.
}

\section{Dr. Uttam Kumar Nath ${ }^{1}$ And Dr. Usha Rani Pegu ${ }^{2}$.}

1. Assistant Professor, Department of Medicine, Jorhat Medical College \& Hospital, Jorhat(JMCH), Assam, Pin 785001.

2. Associate Professor, Department of Medicine, Jorhat Medical College \& Hospital (JMCH), Jorhat, Assam, Pin-785001.

\section{Manuscript Info}

.........................

Manuscript History

Received: 02 June 2019

Final Accepted: 04 July 2019

Published: August 2019

Key words:-

Lean type 2 diabetes mellitus, microvascular,blood glucose.

\section{Abstract}

Background: Diabetes mellitus is the most common metabolic disorder all over the world. Though type 2 diabetes mellitus commonly occurs in subjects who are obese and insulin resistant, obesity defined by body mass index (BMI) is not a common feature in developing countries like India (only about 30\%) as compared to developed countries $(60 \%-80 \%)$ and rather a substantial number of these non obese were actually of low body weight or 'Lean' $(\mathrm{BMI}<18.5)$.

Aim and objectives : To evaluate the microvascular complications in lean type $2 \mathrm{DM}$ with special reference to glycemic and lipid profile , and to compare it with normal body weight, overweight and obese type 2 diabetes mellitus .

Materials and Methods: 74 Type 2 DM patients were divided into four groups according to BMI . Group I(Lean). Group II (normal Body Weight), Group III(Over weight), and Group IV(Obese)

Results: Among the micro vascular complications, the Neuropathy was significantly higher $(75 \%)$ in Lean than other groups. The Lean group had a lower prevalence of Retinopathy (40\%) and Nephropathy(5\%). A significantly severe hyperglycaemia was noted in the Lean group as compared to other groups in both the fasting state as well as the 2 hour post-prandial state. The total cholesterol in the Lean and the Normal Body Weight group was significantly lower than that of the Overweight group. Lean group had significantly lower triglyceride level as compared to Obese group. Triglyceride level increased significantly as BMI increases.

Conclusion: Lean type 2 DM had more severe hyperglycaemia, higher risk of neuropathy, but had a patient friendly lipid profile .Further epidemiological studies with large number of patients are needed to look specially for complications as well as the genetic, immunological and hormonal status to find out the aetiopathogenesis leading to development of Lean type 2 diabetes mellitus .

Copy Right, IJAR, 2019,. All rights reserved.
Corresponding Author:-Dr Usha Rani Pegu Address -Associate Professor, Department Hospital,Jorhat(JMCH),Assam,Pin785001. of Medicine, Jorhat Medical College \& 


\section{Introduction:-}

Diabetes mellitus is known since antiquity. Diabetes mellitus is the most common metabolic disorder all over the world. The incidence is showing an alarming rise in developing countries particularly in India. It is one of the important diseases which affect all the ethnic and geographic population of the world. Though type 2 diabetes mellitus commonly occurs in subjects who are obese and insulin resistant, obesity defined by body mass index (BMI) is not a common feature in developing countries like India (only about 30\%) as compared to developed countries $(60 \%-80 \%)$ and rather a substantial number of these non obese were actually of low body weight or 'Lean' (BMI<18.5). ${ }^{\mathbf{4} 6}$ Indian patients are lean (Lower BMI) but centrally obese with varying waist - hip ratio. ${ }^{8}$ The significant reduction of whole body glucose disposal in obese and lean patients substantiate the pathogenic role of insulin resistance. ${ }^{5}$ Hyperglycaemia is one of the main marker of insulin resistance, even in diabetics selected to be lean or low bodyweight. There is a strong genetic inheritance in type 2 DM lean patients. High prevalence (62\%) of diabetes in families of diabetic patients is a unique and significant finding in the Indian population. ${ }^{7}$ Analyses of data from various parts of India have revealed the prevalence of lean type 2 DM varied from $11 \%$ to $25 \%$. Its prevalence varies depending on types of population, ethnic origin and geo-political situation under study. Ever since the early sixties, studies have described the subgroup of elderly type 2 DM who were of low body weight. It has been observed that these lean groups of type $2 \mathrm{DM}$, which forms a relatively large group have distinctive clinical characteristics. They manifest with visible different presentation, morbidity and mortality patterns as well as biochemical profile and they continue to be lean even after years of good glycaemic control.

Dyslipidemia is common in DM, as both insulin deficiency and resistance affects enzymes and pathways of lipid metabolism ${ }^{2}$. Diabetic dyslipidaemia is characterized by raised triglycerides, low high-density lipoprotein, raised apo-B, and small dense low density lipoprotein particles. It may be present at the diagnosis of type 2DM and it is a component of the metabolic syndrome. Epidemiological studies have shown that, compared to lean individuals, very obese men and women (body mass index >35) have several folds increase in probability of developing Type 2 diabetes ${ }^{1}$.

Even through lean people constitutes a major group of type 2 DM in India, there are no major published studies done on lean body weight or lean type2 DM patient in this upper Assam part of north-east India where there is an interesting confluence of various ethnic groups .

So keeping view of this background the aim and objectives of the study was to evaluate the microvascular complications in lean type $2 \mathrm{DM}$ with special reference to glycemic and lipid profile , and to compare it with normal body weight, overweight and obese type 2 diabetes mellitus .

\section{Materials and Methods:-}

The study was conducted for a duration of one year on patients of type 2 diabetes mellitus (DM) diagnosed according to ADA criteria, attending both out-patient and in-patient department in different medicine units of a tertiary care teaching hospital in North East India after clearance of institutional ethics commitee. Patients were selected randomly and written informed consent was obtained.

\section{Inclusion Criteria}

1. Both previously diagnosed and newly diagnosed type $2 \mathrm{DM}$ patients

2. Patient over 30 years of age irrespective of sex.

\section{Exclusion Criteria}

1. Below 30 years of age irrespective of sex, patients presenting with ketoacidosis or had a past history of ketoacidosis.

2. Patients with history suggestive of pancreatic disease or who on investigation showed evidence of disease of pancreas

3. Pregnant women and patient with Chronic alcoholic ,hepatic disorders

4. Patient with history of malignancy, tuberculosis and acquired immunodeficiency syndrome.

\section{Grouping of cases}

Body mass index (BMI) or Quetelet Index is a statistical measure of the weight of a person scaled according to height. ${ }^{3}$ Height without shoes in meters and weight in $\mathrm{kg}$ were recorded and accordingly BMI was calculated in all 
the cases that were included in the study. Consensus statements from the International Workshop on types of diabetes peculiar to the tropics, Oct' 1995 stated that BMI $<18.5$ is to be taken as lean both in males and females.

BMI was calculated by the Formula:

Weight $(\mathrm{kg})$

After calculating the BMI in all c:

$\mathrm{BMI}=[\text { Height }(\mathrm{m})]^{2}$

\begin{tabular}{|l|l|l|}
\hline BMI & Group of diabetes & Patient group \\
\hline$<18.5$ & Lean & Group I \\
$18.5-24.9$ & Normal body weight (NBW) & Group II \\
$25-29.9$ & Over weight & Group III \\
$30-39.9$ & Obese & Group IV \\
\hline
\end{tabular}

A detailed history was taken regarding age of onset, duration, family history, dietary pattern, presenting complaints at the time of diagnosis. and clinical examination was done to find out any complications. Apart from routine biochemical test, blood glucose (both fasting and post-prandial), and fasting lipid profile were analyzed in all the groups.

Nephropathy was diagnosed on basis of proteinuria in the absence of urinary tract infection. Neuropathy was diagnosed base on subjective symptoms or objective evidence in the form of loss of ankle jerk or glove and stocking type of anaesthesia and monofilament test. Ophthalmoscopy was done to diagnose diabetic retinopathy.

\section{Results and Observations:-}

A total of 74 type 2 DM patients selected randomly, out of which 20 (27.02\%) were found to be Lean, 36 (48.68\%) were Normal body weight(NBW), $12(16.21 \%)$ were Overweight and $6(8.1 \%)$ were Obese .

\section{FIG 1: 3-D PIE DIAGRAM SHOWING PREVALENCES OF LEAN, NBW, OVERWEIGHT \& OBESE TYPE 2 DM}

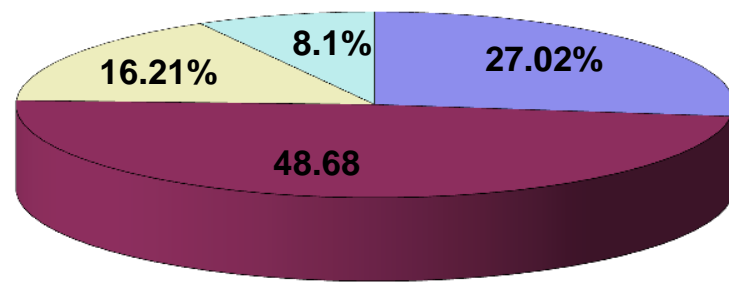

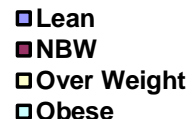

口Obese

\section{Sex distribution of the study groups:}

Out of 74 cases , $48(64.86 \%)$ were males and $26(35.13 \%)$ were females. In the Lean group of type 2 DM $13(65 \%)$ were males and 7 (35\%) were females. In the NBW group $26(72.22 \%)$ were found to be males and $10(22.77 \%)$ were females. Similarly, of the 12 overweight cases $7(58.33 \%)$ cases were males and $5(41.66 \%)$ cases were females and of the $6(8.10 \%)$ case of Obese $2(33.33 \%)$ were male and $4(66.66 \%)$ were females. So the male preponderance of cases were noticed in all the four groups except obese group where female cases were predominant.

Table 1:-Fasting blood glucose in all four category of type 2 DM:

\begin{tabular}{|l|l|l|l|}
\hline Category of type 2 DM & $\begin{array}{l}\text { Fastingblood glucose } \\
(\mathrm{mg} / \mathrm{dl})\end{array}$ & $\begin{array}{l}\text { Male } \\
(\mathrm{mg} / \mathrm{dl})\end{array}$ & $\begin{array}{l}\text { Female } \\
(\mathrm{mg} / \mathrm{dl})\end{array}$ \\
\hline Lean & $316.10 \pm 101.97$ & $326.77 \pm 106.88$ & $296.29 \pm 96.82$ \\
\hline Normal body weight & $185.81 \pm 33.91$ & $189.38 \pm 31.25$ & $176.50 \pm 40.33$ \\
\hline Over weight & $276.67 \pm 68.77$ & $267.57 \pm 57.43$ & $289.40 \pm 87.82$ \\
\hline Obese & $245.33 \pm 53.15$ & $277.50 \pm 67.18$ & $229.25 \pm 46.57$ \\
\hline
\end{tabular}


Fasting blood glucose (after 8 hours of overnight fasting) was significantly higher in the Lean group of type 2 DM in comparison to the other three groups. The difference was more marked between the Lean group and the NBW group. The same observation was found between the male and between the females of the four groups without any significant difference between male and female of a same group.

Table 2:-Post prandial blood glucose in all four category of type 2 DM:

\begin{tabular}{|l|l|l|l|}
\hline Category of type 2 DM & $\begin{array}{l}\text { Post prandial blood } \\
\text { glucose }(\mathrm{mg} / \mathrm{dl})\end{array}$ & $\begin{array}{l}\text { Male } \\
(\mathrm{mg} / \mathrm{dl})\end{array}$ & $\begin{array}{l}\text { Female } \\
(\mathrm{mg} / \mathrm{dl})\end{array}$ \\
\hline Lean & $391.40 \pm 97.46$ & $417.54 \pm 87.76$ & $342.86 \pm 102.21$ \\
\hline Normal body weight & $300.28 \pm 60.29$ & $298.50 \pm 49.04$ & $304.90 \pm 86.17$ \\
\hline Overweight & $344.33 \pm 37.17$ & $352.00 \pm 40.59$ & $333.60 \pm 32.88$ \\
\hline Obese & $336.86 \pm 35.74$ & $345.50 \pm 62.93$ & $332.50 \pm 27.09$ \\
\hline
\end{tabular}

The Lean group had severe hyperglycaemia and it was significantly more than the NBW, Overweight and Obese group $(\mathrm{p}<0.05)$. The NBW group had the least hyperglycaemia, followed by the obese and overweight groups. There was no significant difference between males and females of a same group.

Table 3:-Fasting cholesterol in all four category of type 2 DM:

\begin{tabular}{|l|l|l|l|}
\hline Category of type 2 DM & $\begin{array}{l}\text { Total fasting cholesterol } \\
\text { level }(\mathrm{mg} / \mathrm{dl})\end{array}$ & $\begin{array}{l}\text { Male } \\
(\mathrm{mg} / \mathrm{dl})\end{array}$ & $\begin{array}{l}\text { Female } \\
(\mathrm{mg} / \mathrm{dl})\end{array}$ \\
\hline Lean & $189.05 \pm 10.10$ & $190.23 \pm 9.00$ & $186.86 \pm 12.33$ \\
\hline Normal body weight & $189.75 \pm 14.11$ & $188.35 \pm 12.96$ & $193.40 \pm 16.94$ \\
\hline Over weight & $201.42 \pm 14.67$ & $198.14 \pm 16.92$ & $206.00 \pm 10.84$ \\
\hline Obese & $192.67 \pm 28.10$ & $169.50 \pm 6.36$ & 27.67205 .24 \\
\hline
\end{tabular}

There was significantly higher mean cholesterol level in the Overweight group as compared to the Lean and NBW group ( $\mathrm{p}<0.05)$. There was no significant difference in the cholesterol levels between the Lean, NBW and Obese groups. This findings were also reflected in the male and female patients of the corresponding groups. There was no significant difference between the cholesterol levels of male and female diabetics in respective groups.

Table 4:-Triglyceride level in all four category of type 2 DM:

\begin{tabular}{|l|l|l|l|}
\hline Category of type 2 DM & $\begin{array}{l}\text { Mean Triglyceride level } \pm \\
\text { 1 SD }(\mathrm{mg} / \mathrm{dl})\end{array}$ & $\begin{array}{l}\text { Male } \\
(\mathrm{mg} / \mathrm{dl})\end{array}$ & $\begin{array}{l}\text { Female } \\
(\mathrm{mg} / \mathrm{dl})\end{array}$ \\
\hline Lean & $136.40 \pm 36.41$ & $134.23 \pm 37.76$ & $140.43 \pm 36.31$ \\
\hline Normal body weight & $146.72 \pm 41.49$ & $147.35 \pm 45.28$ & $140.71 \pm 36.55$ \\
\hline Over weight & $163.00 \pm 39.18$ & $175.71 \pm 42.51$ & $145.20 \pm 28.83$ \\
\hline Obese & $174.33 \pm 35.01$ & $151.00 \pm 43.48$ & 29.29186 .0 \\
\hline
\end{tabular}

Lean group had significantly lower triglyceride levels with a mean of $136.40 \pm 36.41$ compared to Obese group $(p<0.05)$. Male had higher triglyceride level then female in all the groups except Lean where mean triglyceride level in female was higher. There was no significant different statistically between male and female in all the groups.

Table 5:-HDLc in all four category of type 2 DM:

\begin{tabular}{|l|l|l|l|}
\hline Category of type 2 DM & $\begin{array}{l}\text { Mean } \\
\text { HDLc } \pm 1 \mathrm{SD} \\
(\mathrm{mg} / \mathrm{dl})\end{array}$ & $\begin{array}{l}\text { Male } \\
(\mathrm{mg} / \mathrm{dl})\end{array}$ & $\begin{array}{l}\text { Female } \\
(\mathrm{mg} / \mathrm{dl})\end{array}$ \\
\hline Lean & $46.20 \pm 7.02$ & $46.00 \pm 07.16$ & $46.57 \pm 07.28$ \\
\hline Normal body weight & $46.00 \pm 7.53$ & $45.65 \pm 7.56$ & $46.90 \pm 07.77$ \\
\hline Over weight & $46.92 \pm 10.23$ & $47.57 \pm 06.00$ & $46.00 \pm 15.23$ \\
\hline Obese & $43.83 \pm 04.83$ & $43.50 \pm 03.54$ & $05.89 \mathbf{4 4 . 0}$ \\
\hline
\end{tabular}

The mean HDLc levels which were comparable without any significant difference in all the groups ( $\mathrm{p}>0.05$ ). No significant difference was seen between male and female in all the groups. 
Table 6:-LDLc in all four category of type 2 DM:

\begin{tabular}{|l|l|l|l|}
\hline Category of type 2 DM & $\begin{array}{l}\text { Mean } \\
\text { LDLc } \pm 1 \mathrm{SD} \\
(\mathrm{mg} / \mathrm{dl})\end{array}$ & $\begin{array}{l}\text { Male } \\
(\mathrm{mg} / \mathrm{dl})\end{array}$ & $\begin{array}{l}\text { Female } \\
(\mathrm{mg} / \mathrm{dl})\end{array}$ \\
\hline Lean & $117.07 \pm 15.37$ & $117.38 \pm 09.53$ & $116.49 \pm 23.79$ \\
\hline Normal body weight & $114.94 \pm 16.18$ & $113.55 \pm 16.14$ & $118.56 \pm 16.55$ \\
\hline Over weight & $121.20 \pm 14.21$ & $114.26 \pm 1.35$ & $130.92 \pm 13.85$ \\
\hline Obese & $120.20 \pm 25.53$ & $114.50 \pm 09.48$ & $123.05 \pm 32.00$ \\
\hline
\end{tabular}

The fasting LDLc level in all the study groups. There was no significant difference seen between the Lean and other groups ( $p>0.05$ ). Similarly all the values were comparable between male and females in all the groups without any significant difference.

Table 7:-Neuropathy in different category of type 2 DM

\begin{tabular}{|l|l|l|l|l|}
\hline $\begin{array}{l}\text { Category } \\
\text { of } \\
\text { type 2 DM }\end{array}$ & $\begin{array}{l}\text { Total } \\
\text { No. of cases }\end{array}$ & $\begin{array}{l}\text { Total cases with } \\
\text { nephropathy } \\
(\%)\end{array}$ & $\begin{array}{l}\text { Male } \\
(\%)\end{array}$ & $\begin{array}{l}\text { Female } \\
(\%)\end{array}$ \\
\hline Lean & 20 & $15(75)$ & $8(61.54)$ & $7(100)$ \\
\hline Normal body weight & 36 & $15(41.66)$ & $8(30.77)$ & $7(70)$ \\
\hline Over weight & 12 & $7(58.33)$ & $4(57.14)$ & $3(60)$ \\
\hline Obese & 6 & $3(80)$ & $1(50)$ & $2(50)$ \\
\hline
\end{tabular}

In the Lean group 15 cases (75\%) had neuropathy, In the NBW, Overweight and Obese had neuropathy in 41.66\%, $58.33 \%$ and $50 \%$ of cases respectively. Thus it is seen that the incidence of neuropathy was much higher in the Lean group compared to the other three groups, in fact significantly higher as compared to the NBW group $(\mathrm{p}<0.05)$.

It is also seen from the table that the incidence of neuropathy was higher in the females as compared to the males in an individual groups except in Obese where male and female incidence was same between each other.

Table 8:-Nephropathy in all four study group:

\begin{tabular}{|l|l|l|l|l|}
\hline $\begin{array}{l}\text { Category } \\
\text { of } \\
\text { type 2 DM }\end{array}$ & $\begin{array}{l}\text { Total } \\
\text { No. of cases }\end{array}$ & $\begin{array}{l}\text { Total cases with } \\
\text { nephropathy } \\
(\%)\end{array}$ & $\begin{array}{l}\text { Male } \\
(\%)\end{array}$ & $\begin{array}{l}\text { Female } \\
(\%)\end{array}$ \\
\hline Lean & 20 & $1(5)$ & 1 & 0 \\
\hline Normal body weight & 36 & $3(8.33)$ & 2 & 1 \\
\hline Over weight & 12 & $3(25)$ & 2 & 1 \\
\hline Obese & 6 & $2(33.33)$ & 1 & 1 \\
\hline
\end{tabular}

The incidence of nephropathy in the Lean group of type 2 DM were comparatively lower (5\%) than the other three group. But there was no significant difference between them. It is also seen that the incidence of nephropathy was highest in the Obese group. The incidence in the NBW group was lower than the Overweight and Obese groups but was not significantly higher than the Lean group.

Table 9:-Retinopathy in different category of type $2 \mathrm{DM}$ :

\begin{tabular}{|c|c|c|c|c|}
\hline Category of type $2 \mathrm{DM}$ & $\begin{array}{l}\text { Type of } \\
\text { retinopathy }\end{array}$ & $\begin{array}{l}\text { Total } \\
(\%)\end{array}$ & $\begin{array}{l}\text { Male } \\
(\%)\end{array}$ & $\begin{array}{l}\text { Female } \\
(\%)\end{array}$ \\
\hline $\begin{array}{l}\text { Lean } \\
(\mathrm{n}=20)\end{array}$ & $\begin{array}{ll}\text { No Retinopathy Non } \\
\text { proliferative } \\
\text { Proliferative }\end{array}$ & $\begin{array}{l}12(60) \\
5(25) \\
3(15) \\
\end{array}$ & $\begin{array}{l}8(61.53) \\
3(23.07) \\
2(15.38) \\
\end{array}$ & $\begin{array}{l}4(57.14) \\
2(28.57) \\
1(14.28) \\
\end{array}$ \\
\hline $\begin{array}{l}\text { Normal body } \\
\text { weight }(n=36)\end{array}$ & $\begin{array}{ll}\text { No Retinopathy Non } \\
\text { proliferative } \\
\text { Proliferative }\end{array}$ & $\begin{array}{l}18(50) \\
16(44.44) \\
2(5.55)\end{array}$ & $\begin{array}{l}16(61.53) \\
9(34.61) \\
1(3.85)\end{array}$ & $\begin{array}{l}2(20) \\
7(70) \\
1(10)\end{array}$ \\
\hline $\begin{array}{l}\text { Over weight } \\
(\mathrm{n}=12)\end{array}$ & $\begin{array}{l}\text { No Retinopathy } \\
\text { proliferative } \\
\text { Proliferative }\end{array}$ & $\begin{array}{l}3(25) \\
6(50) \\
3(25)\end{array}$ & $\begin{array}{l}2(28.57) \\
3(42.85) \\
2(28.57)\end{array}$ & $\begin{array}{l}1(20) \\
3(60) \\
1(20)\end{array}$ \\
\hline
\end{tabular}




\begin{tabular}{|l|l|l|l|l|}
\hline $\begin{array}{l}\text { Obese } \\
(\mathrm{n}=6)\end{array}$ & $\begin{array}{l}\text { No Retinopathy Non } \\
\text { proliferative }\end{array}$ & $1(16.66)$ & 0 & $1(25)$ \\
& Proliferative & $2(50)$ & $1(50)$ & $2(50)$ \\
\hline
\end{tabular}

It is observed from the table that in the Lean group of a total of 20 cases, $8(40 \%)$ had retinopathy. In the NBW group, of a total of 36 cases, 18 cases (50\%) had retinopathy. But in the Overweight and Obese group $9(75 \%)$ and 5 (83.3\%) cases had retinopathy respectively. So it was obviously seen that the incidence retinopathy in the Lean group was significantly lower than the Overweight and Obese groups $(\mathrm{p}<0.05)$. The Lean group and the NBW group had a comparable incidence without any significant.

The incidences of retinopathy in males and females of an individual group were comparable except in the NBW group where females had a significantly higher incidence of retinopathy $(\mathrm{P}<0.05)$.

Table 10:-Incidence of microvascular complications in all four study groups:

\begin{tabular}{|l|l|l|l|l|}
\hline Complication & $\begin{array}{l}\text { Lean } \\
(\%)\end{array}$ & $\begin{array}{l}\text { Normal body } \\
\text { weight } \\
(\%)\end{array}$ & $\begin{array}{l}\text { Overweight } \\
(\%)\end{array}$ & $\begin{array}{l}\text { Obese } \\
(\%)\end{array}$ \\
\hline Nephropathy & 5 & 8.33 & 25 & 33.33 \\
\hline Retinopathy & 40 & 50 & 75 & 83.30 \\
\hline Neuropathy & 75 & 41.66 & 58.33 & 50 \\
\hline
\end{tabular}

It is evident from the above table that the Lean group of type 2 DM had significantly lower incidence of retinopathy than the other groups especially the Overweight and Obese group. But the incidence neuropathy were much higher in the Lean group than the other groups. The incidence of neuropathy in the Lean was significantly higher than NBW group $(\mathrm{P}<0.05)$.

\section{Discussion:-}

The prevalence of Lean type $2 \mathrm{DM}$ in this present study was found to be $27.02 \%$. Tripathy and $\mathrm{Kar}_{\mathrm{et}} \mathrm{al}^{11}$ had noticed that $27 \%$ of their diabetics were elderly Lean type. Similarly S.Das et al ${ }^{4}$ and P. Dharamaranjan et al ${ }^{10}$ found prevalence Lean type $2 \mathrm{DM} 23.9 \%, 24.8 \%$ respectively. These findings are comparable to the present study.

\section{Sex distribution:}

Out of the total 74 cases $48(64.86 \%)$ were males and $26(35.13 \%)$ were females. So a gross male preponderance was noticed in all the four groups of type 2 DM. Tripathy and Kar also noticed that there was a male preponderance where $85.5 \%$ were males and only $14.5 \%$ of patients were females. V. Mohan et $\mathrm{al}^{12}$ in a study of a large group of 9873 cases of type $2 \mathrm{DM}$ found $62.6 \%$ males and $37.4 \%$ of females. So the present study is comparable to the V.Mohan et al study. Das S. et al and P.Dharmarajan et al studies have also found similar results. Since all of these were hospital based studies the significant male preponderance may be due primarily to increases reporting of male cases to the hospitals.

\section{Body Mass Index (BMI):}

Analysis of the BMI showed that there was a substantial variation in the mean BMI's between the four study groups. The Lean group had a BMI of $16.75 \pm 1.11$. P. Dharamarajan et al found the mean BMI of the Lean group at presentation to be $17.7 \pm 1.9$. Gupta R Singh et al ${ }^{13}$ study found that mean BMI in Lean group to be $17.69 \pm 2.49$. S. Das et al also found the mean BMI of the Lean group to be 17.4 \pm 1.4 . So in the present study the BMI is almost similar to all the above mention studies.

\section{Glycaemic status:}

One of the characteristic findings of the present study was that the Lean group had a significantly severe hyperglycaemia both in the fasting as well as the 2-hour post glucose load states. The fasting level was $316.1 \pm$ $101.97 \mathrm{mg} / \mathrm{dl}$ in the Lean as compared to $185.81 \pm 33.91,276.67 \pm 68.77$ and $245.33 \pm 53.15 \mathrm{mg} / \mathrm{dl}$ in the NBW, Overweight and Obese groups respectively. Similarly the post glucose load value was $391.40 \pm 97.46 \mathrm{mg} / \mathrm{dl}$ in the Lean as compared to $300.28 \pm 60.29,344.33 \pm 37.17$ and $336.86 \pm 35.74 \mathrm{mg} / \mathrm{dl}$ in the NBW, Overweight and Obese 
groups. This finding was consistent with the findings in the other studies. V. Mohan et al found the mean fasting level to be $208.8 \pm 88 \mathrm{mg} / \mathrm{dl}$ in the Lean as compared to $171 \pm 62 \mathrm{mg} / \mathrm{dl}, 174 \pm 51$ and $165 \pm 54 \mathrm{mg} / \mathrm{dl}$ in the NBW, Overweight and Obese groups respectively. Similarly the post prandial blood glucose level were $313.10 \pm 52.04$ $\mathrm{mg} / \mathrm{dl}, 277.50 \pm 41.18,264.90 \pm 56 \mathrm{mg} / \mathrm{dl}$ and, $259.12 \pm 69 \mathrm{mg} / \mathrm{dl}$ in the Lean, NBW, overweight and obese groups respectively. S. Das et al found the fasting plasma glucose to be $183.7 \pm 63.5 \mathrm{mg} / \mathrm{dl}$ in the Lean and $110 \pm 34.78$, $122.8 \pm 38$ and $147.9 \pm 43.3 \mathrm{mg} / \mathrm{dl}$ in the NBW, Overweight and Obese groups. P. Mukhyaprarna et al ${ }^{9}$ found fasting blood glucose level to be $177.08 \pm 105.1,152.80 \pm 54.20,156.18 \pm 55.44$ and $155.16 \pm 35.18 \mathrm{mg} / \mathrm{dl}$ in the Lean, NBW, Overweight and Obese groups and post prandial plasma glucose value was $288.45 \pm 111.93$ in Lean as compare to $236.58 \pm 81.75,226.5 \pm 71.23$ and $238.17 \pm 62.92 \mathrm{mg} / \mathrm{dl}$ in NBW, Overweight and Obese groups. P. Dharamarajan et al found the FPG in the Lean group to be $217 \pm 97.28 \mathrm{mg} / \mathrm{dl}$. So this severe hyperglycaemia may be a characteristic of the Lean group of type $2 \mathrm{DM}$.

\section{Fasting Lipid Profile:}

On analysis of the fasting total cholesterol in the study it was seen that the Lean group had the lowest cholesterol level as compared to the other three groups and significantly so than the Overweight and Obese group $(\mathrm{p}<0.05)$. The mean total cholesterol levels were $189.05 \pm 10.10,189.75 \pm 14.11,201.42 \pm 14.6$ and $192.67 \pm 28.10 \mathrm{mg} / \mathrm{dl}$ in the Lean, NBW, Overweight and Obese groups respectively. V. Mohan et al also noticed that the Lean group had a significantly lower cholesterol level than the other groups. The mean cholesterol were $189 \pm 42 \mathrm{mg} / \mathrm{dl}$ in the Lean, $202 \pm 38 \mathrm{mg} / \mathrm{dl}$ in the NBW and $206 \pm 41 \mathrm{mg} / \mathrm{dl}$ in the Overweight group. P Mukhyaprana et al study also found lower fasting cholesterol level in Lean type $2 \mathrm{DM}$ with and mean of $174.27 \pm 68.66 \mathrm{mg} / \mathrm{dl}$. So this present study is comparable to the above studies.

The triglyceride level was significantly lower in Lean then the obese group $(\mathrm{P}<0.05)$ in the present study. As BMI increases the triglyceride level were also increases with a mean level in the Lean and Obese is $136.40 \pm 36.41$ and $174.33 \pm 35.01 \mathrm{mg} / \mathrm{dl}$ respectively.

There was no statistically significant difference in the HDLc level between Lean and other groups in this study with a mean level of $46.20 \pm 7.02 \mathrm{mg} / \mathrm{dl}$ in Lean group and $43.83 \pm 4.83 \mathrm{mg} / \mathrm{dl}$ in Obese. Das. $\mathrm{S}$ et al also showed total cholesterol and triglyceride levels were lower in Lean while HDLc were similar to Obese type 2 DM. P. Mukhyaprana et al also found triglyceride and HDLc levels in Lean type $2 \mathrm{DM}$ to be $124.28 \pm 57.88 \mathrm{mg} / \mathrm{dl}$ and $44 \pm$ $15.63 \mathrm{mg} / \mathrm{dl}$ respectively. S. Das et al also found that the HDLc cholesterol was never low even at a glycaemically uncontrolled state.

Regarding the LDLc, in this study there was no significant difference in LDLc level in all the groups with a mean LDLc level of $117.07 \pm 15.37,114.94 \pm 16.18,121.2 \pm 14.21$ and $120.20 \pm 25.53 \mathrm{mg} / \mathrm{dl}$ in Lean, NBW, Overweight and Obese respectively. P. Mukhyaprarna et al study found a mean of $97.37 \pm 57.66 \mathrm{mg} / \mathrm{dl}$ of HDLc in the Lean group. So as a whole, the Lean group was found to have a favourable lipid profile and did not have hyperlipidaemia that is conducive to development of atherosclerosis and coronary artery disease.

\section{Microvascular complications:}

The Lean group had a very high incidence of Neuropathy (75\%) as compared to NBW group (41.66\%), Overweight group (58.33\%) and Obese group (50\%). The incidence of Nephropathy and Retinopathy were lower in the Lean group. Nephropathy was found in 5\% in the Lean as compared to $8.33 \%$ in the NBW, $25 \%$ in the Overweight group and 33.33 in Obese group. Retinopathy was lower in the Lean (40\%) than the NBW (50\%), Overweight (75\%) and Obese $(83.3 \%)$ groups. The incidence of Retinopathy in the females of the NBW group were significantly higher than the males of that group $(\mathrm{P}<0.05)$. This finding was difficult to explain, as all the other known parameters were comparable between the males and female of the NBW group.

Barma PD et $\mathrm{al}^{14}$ observed peripheral neuropathy in $70 \%$, retinopathy in $25 \%$ and nephropathy in $13 \%$ of lean type 2 DM patients, S. Das et al found the incidence of Neuropathy (49.4\%) to be high in his study group and retinopathy were found to be low. V. Mohan et al also found increased incidence of Neuropathy (44.6\%) as well as Retinopathy (44.09\%) in the Lean group. Again P. Dharamarajan et al found a high incidence of neuropathy (42\%) and lower incidences of nephropathy (6.3\%), Retinopathy (5.5\%). 
It is difficult to explain and compare all the variations seen in the studies done on the complication profile. But one very prominent finding in all the studies is the high incidence of neuropathy in the Lean group. This in part can be explained by the severe hyperglycaemia seen in this group.

\section{Summary:}

The prevalence of Lean type 2 DM found in this present hospital based study was $27.02 \%$ of the total type 2 DM patients. Most of the type 2 DM fall in the Normal Body Weight Category. Only $8.10 \%$ of the total type 2 DM cases were Obese.There was a significant male preponderance of cases in all the groups of type 2 DM except in Obese where female were predominantly present.

A significantly severe hyperglycaemia was noted in the Lean group as compared to the Normal Body Weight, Overweight and Obese groups in both the fasting state as well as the 2 hour post-prandial state. The glycaemic profile was best in the Normal Body Weight group.

The total cholesterol in the Lean and the Normal Body Weight group was significantly lower than that of the Overweight group. Lean group had significantly lower triglyceride level as compared to Obese group. Triglyceride level increased significantly as BMI increases.

Among the microvascular complications, the Neuropathy was much higher in the Lean group. In fact the prevalence of neuropathy was significantly higher in Lean than Normal Body Weight group. The Lean group had a lower prevalence of Nephropathy, and Retinopathy.

\section{Conclusion:-}

From this study we reasonably conclude that a substantial proportion of type $2 \mathrm{DM}$ a Lean body habitus. The Lean type $2 \mathrm{DM}$ is a distinct clinical and metabolic entity and is different from the classical Normal body weight, Overweight and Obese type $2 \mathrm{DM}$. The glycaemic profile was the main area of characteristic difference and it influences the natural course of the Lean group. They have more severe hyperglycaemia, have higher risk of neuropathy, but have a patient friendly lipid profile and related advantages. As it is a hospital based study and has limitations, further epidemiological studies are needed to look specially for complications as well as the genetic, immunological and hormonal status will also be required to find out the aetiopathogenesis leading to development of Lean type 2 diabetes mellitus .

\section{References:-}

1. Ahuja MMS: Diabetes Care in India, the reality and a dream. In: Kapur A(ed). Proceedings of the second NovoNordisk diabetes update. Health Care Communication, Bombay, 1993: 15-20.

2. Alvin C. Powers: Diabetes Mellitus; 398; 2875-82 ;Harrison's principles of internal medicine vol. (II), $20^{\text {th }}$ ed.

3. BMI-From Wikipedia, the Free encyclopedias.

4. Das S. Identity of Lean-NIDDM: Clinical, metabolic and hormonal status. In: Kochupillai N (ed). Advances in Endocrinology, Metabolism and Diabetes, Vol. 2. Macmillan: Delhi, India 1994: 42-53.

5. DeFronzo RA: Pathogenesis of Type 2 Diabetes. In: Am Diab Assn: Anuual Rev Diab 1998; 1-93.

6. Shay BK: Profile of lean-NIDDM as seen in Hyderabad. IN: Kapur A (ed). Proceedings of the Novo - Nordisk Diabetes Update. Health Care Communication, Bombay 1993: 147-51

7. Viswanathan M: Diabetes in Tropics, DIAMET 36-1994, 5.

8. Yajnik CS: Diabetic practice; special IJIM issue Oct 1996; 10:

9. Prabhu Mukhyaprana M, Sudha Vidyasagar, Shashiliran U: Clinical profile of type 2 diabetes mellitus and body mass index - is there any correlation?; Calicut Medical Journal 2004; 2(4): e3.

10. Dharmaranjan. P, Sundaram. A, Venkatraman. S, Madhavan. R, Rajendhiran. N, Manjula. N, Renuka. A, Hariharan. R.S: Clinical Profileof Lean NIDDM subjects: Noro- Nordisk Diabetes Update: 1994 Proceedings: Health Care Communications: Pg: 105-107.

11. Tripathy B.B, Kar. B.C: Observation on Clinical Patterns of Diabetes mellitus in India: 1965: Vol 14: No 7: Pg: 404412.

12. Mohan V, Vijayaprabha R, Rema M, et al: Clinical Profile of Lean NIDDM in South India. Diabetes Res Clin Pract 1997; 38:101-8.

13. Gupta Rajinder singh, Gupta MM, Kaurk, Rao HK, Singh AR, Goyal A.: Journal of Association of physician Dec. 2003, vol. 51; 25-26.

14. Barma PD, Ranabir S, Prasad L, Singh TP. Clinical and biochemical profile of lean type 2 diabetes mellitus. Indian J Endocrinol Metab. 2011;15(Suppl 1):S40-S43. doi:10.4103/2230-8210.83061. 